\title{
Why do Situational Interviews Predict Job Performance? The Role of Interviewees' Ability to Identify Criteria
}

\author{
Pia V. Ingold • Martin Kleinmann • \\ Cornelius J. König • Klaus G. Melchers • \\ Chad H. Van Iddekinge
}

Published online: 17 June 2014

(C) Springer Science+Business Media New York 2014

\begin{abstract}
Purpose This study aimed at shedding light on why situational interviews (SIs) predict job performance. We examined an explanation based upon the importance of interviewees' Ability to Identify Criteria (ATIC, i.e., to read the targeted interview dimensions) for SI performance.

Design/Methodology/Approach Data were obtained from 97 interviewees who participated in a mock interview to train for future applications. This approach enabled us to conduct the SIs under standardized conditions, to assess interviewees' ATIC, and at the same time, to collect job performance data from interviewee's current supervisors.

Findings We found that interviewees' ATIC scores were not only positively related to their interview performance, but also predicted job performance as rated by their supervisors. Furthermore, controlling for interviewees'
\end{abstract}

P. V. Ingold $(\varangle) \cdot$ M. Kleinmann

Psychologisches Institut, Universität Zürich, Binzmühlestrasse

14/12, 8050 Zurich, Switzerland

e-mail: p.ingold@psychologie.uzh.ch

C. J. König

Fachrichtung Psychologie, Universität des Saarlandes,

Saarbrücken, Germany

K. G. Melchers

Institut für Psychologie und Pädagogik, Universität Ulm, Ulm, Germany

C. H. Van Iddekinge

College of Business, Florida State University, Tallahassee, FL, USA
ATIC significantly lowered the relationship between performance in the SI and job performance.

Implications Better understanding of the mechanisms that underlie the criterion-related validity of SIs is crucial for theoretical progress and improving personnel selection procedures. This study highlights the relevance of interviewees' ATIC for predicting job performance. It also underscores the importance of constructing interviews to enable candidates to show their criterion-relevant abilities. Originality/Value This study shows that interviewees' ATIC contributes to a better understanding of why the SI predicts job performance.

Keywords Situational interviews - Criterion-related validity - Ability to identify criteria $\cdot$ Job performance

\section{Introduction}

Past research has shown that increasing the structure of selection interviews helps to improve their psychometric properties (e.g., Huffcutt and Arthur 1994; Latham and SueChan 1999; McDaniel et al. 1994; Taylor and Small 2002). Structure has been defined as "the degree of discretion that an interviewer is allowed in conducting the interview" (Huffcutt and Arthur 1994, p. 186) and can accordingly be characterized by the degree of standardization of interview questions, interview administration and response scoring.

Among the many types of structured interviews, the situational interview (SI; Latham et al. 1980) has emerged as one of the most popular formats (e.g., Campion et al. 1997; Motowidlo 1999). Based on goal-setting theory (Locke and Latham 1990), the SI relies on the assumption that intentions predict behavior (Latham et al. 1980). The SI is composed of questions that outline hypothetical 
job-related situations and asks interviewees how they would behave in those situations. Meta-analytic evidence has shown that the criterion-related validity of SIs comes close to that of cognitive ability tests, with mean-corrected correlations that range between .41 and .47 (e.g., Huffcutt and Arthur 1994; Kepes et al. 2012; Latham and Sue-Chan 1999; McDaniel et al. 1994; Taylor and Small 2002).

Although evidence that the SI predicts job performance has existed for quite some time, it is less evident why the SI predicts job performance. The extant research has elaborated several possible explanations, including the standardization of the questions that are asked, the manner in which interviewees' answers are scored, and the potential overlap of the SI with cognitive ability (Maurer et al. 1999; Roth and Huffcutt 2013). This research has provided many valuable insights, but has not yet fully answered the question of why SIs predict job performance.

In the present study, we look at an additional explanation that shifts the focus onto the interactive character of the interview situation. Specifically, it has been argued that interviewees' Ability to Identify Criteria (ATIC; Kleinmann et al. 2011; König et al. 2007; Melchers et al. 2009), hence their ability to discern which dimensions the interviewers seek to evaluate, can affect their performance in the interview. Specifically, ATIC enables interviewees to provide more evaluation-relevant answers, experiences, and behaviors, which in turn may lead to more successful performance in the selection situation. Furthermore, it has been argued that this ability is important not only in the interview and other selection procedures (e.g., assessment centers (ACs)), but on the job as well (Jansen et al. 2013; Kleinmann et al. 2011).

Taken together, we examine whether ATIC helps to account for the criterion-related validity of SI ratings. Developing knowledge on this matter is important for research as well as for practice because of several reasons. For research, the present study provides conceptual insights into why SIs predict performance. Thereby, it adds to the recent research focus on the interactive nature of interviews by contributing empirical evidence on whether individual differences in reading situational demands are crucial for both interviewees' performance in the SI and on the job. For practice, this knowledge may enable organizations to design selection interviews that better assess candidates' job-relevant individual differences. The present results also may provide guidance as to whether it may be useful to measure ATIC in SIs or other selection procedures.

\section{ATIC as an Additional Explanation for Why SIs Predict Job Performance}

Researchers have put forth various explanations for the relationship between interview performance and job performance (see Harris 1999; Macan 2009, for an overview). These explanations apply to structured interviews in general and SIs in particular as a popular form of structured interviews. One explanation is that structured interview questions measure job-relevant performance dimensions (Huffcutt 2011; Latham and Sue-Chan 1999). Accordingly, a potential reason for why SIs predict job performance is that the dimensions that the interviews are designed to measure are linked to job performance because of a prior job analysis (e.g., Huffcutt 2011; Huffcutt et al. 2001; Motowidlo 1999). Previous research that tested this approach has focused primarily on the internal construct-related validity of the interview by using multitraitmultimethod approaches (Campbell and Fiske 1959). This research tested whether questions assessing the same dimension correlate more strongly than questions assessing different dimensions (e.g., Conway and Peneno 1999; Huffcutt et al. 2001; Melchers et al. 2009; Van Iddekinge et al. 2004). Results of these investigations, however, have been mixed and provide less than conclusive evidence concerning the construct-related validity of structured interviews.

Another explanation is that interview ratings are "saturated" with constructs such as cognitive ability (Berry et al. 2007; Roth and Huffcutt 2013) or personality (Roth et al. 2005). However, meta-analytic results have shown that the relation between interview performance and cognitive ability is only moderate, and that cognitive ability therefore can only account for a limited amount of the SI's criterion-related validity (Berry et al. 2007; Roth and Huffcutt 2013). In a similar vein, meta-analytic results indicate that the relation between structured interview performance and personality is also moderate (Cortina et al. 2000; Roth et al. 2005; Salgado and Moscoso 2002), and hence can only account for part of the SI's criterionrelated validity.

Thus, although these and other explanatory approaches have contributed to our understanding of structured interviews in general as well as to our understanding of the SI in particular, they have not fully addressed the question of why SIs predict job performance. Given that there is a recent emphasis on the interview as a social interaction (e.g., Bangerter et al. 2012; Huffcutt et al. 2011; Levashina et al. 2013; Melchers et al. in press), further understanding can arise from explaining the criterion-related validity from a perspective that acknowledges the content and the interactive nature of interviews. It thus seems beneficial to test this emerging explanation for why SIs predict job performance.

The underlying rationale for this idea rests on the assumption that candidates in selection interviews selectively attend to information that they think is relevant to perform well (Leary and Kowalski 1990). Specifically, interviewees often face a great deal of uncertainty on how to behave in these interviews (Ferris and Judge 1991), 
unless the targeted interview dimensions are explicitly revealed to them (see Klehe et al. 2008). For this reason, candidates' ATIC is relevant for their performance in the interview (Kleinmann et al. 2011; Melchers et al. 2004, 2009). ATIC refers to an individual's ability to correctly identify the dimensions that are measured in selection procedures. Kleinmann et al. (2011), for example, proposed that individuals with higher ATIC can show more dimension-relevant behaviors in selection procedures because they have a better understanding of what is evaluated in these procedures.

ATIC has been conceptualized as a form of contextspecific social effectiveness (Kleinmann et al. 2011) and relates to interviewees' social effectiveness in the interviewee performance model by Huffcutt et al. (2011). Huffcutt et al.'s model adopts the emerging perspective of the interview as an interaction of the interviewer and the interviewee. By doing so, this model elaborates on the nomological network of factors that affect how applicants perform in interviews, including the importance of skills related to social effectiveness. These skills reflect how well individuals read and act in social interactions and can encompass many constructs, among them ATIC.

In line with these suggestions, ATIC has been shown to correlate with interviewees' performance in structured interviews (Griffin 2014; Melchers et al. 2009, 2012), as well as with participants' performance in ACs (e.g., Jansen et al. 2013; Kleinmann 1993; König et al. 2007; Speer et al. 2014). As a first step for testing the ATIC-based explanation, we posit that this will also be true in the present study:

Hypothesis 1 Interviewees' ATIC is positively related to performance in a SI.

Despite empirical findings that emphasize the relevance of ATIC for performance in structured interviews, research concerning the role of ATIC as measured in interviews in predicting job performance is lacking. SI and job situations are similar in that evaluation criteria of performance are often not transparent. For example, there can be considerable ambiguity in terms of how to successfully deal with a SI question and how to successfully deal with a job situation (Seibert et al. 1999).

Accordingly, individuals with a greater ATIC score are more likely to discern criteria for success both in the SI and on the job. This, in turn, should help candidates provide evaluation-relevant answers in the interview, as well as demonstrate evaluation-relevant behaviors on the job. For instance, someone who recognizes the importance of cooperativeness as an evaluation criterion might focus on cooperation when describing how they would approach situations asked about in the SI or make efforts to cooperate (rather than compete) with coworkers on the job.
Moreover, people scoring high on ATIC might also use appropriate self-presentation tactics in the interview and on the job (cf. Barrick et al. 2009). Hence, ATIC may represent a common cause of SI performance and job performance and thereby provide an explanation for why performance in SIs predicts job performance.

In support of this idea, a recent study by Jansen et al. (2013) revealed that participants in an AC who were able to identify the targeted dimensions also received higher job performance ratings. Furthermore, AC scores did not remain a significant predictor of job performance when ATIC scores were partialled out from the relationship between $\mathrm{AC}$ and job performance.

Even though there are several differences between ACs and SIs in general, we assume that ATIC has similar effects for SIs as for ACs. Thus, based on the conceptual reasoning from above and Jansen et al.'s (2013) findings, we aim to test the following hypotheses based on the assumption that interviewees' ATIC contributes to the prediction of job performance. Furthermore, and also in light of the results from Jansen et al. (2013), we suggest that controlling for the criterion-relevant variance of ATIC in the relation of the SI and job performance decreases shared variance of the predictor and criterion. Therefore, we make the following predictions:

Hypotheses 2 Interviewees' ATIC predicts job performance.

Hypothesis 3 The relation between SI performance and job performance will decrease when controlling for interviewees' ATIC.

Moreover, building on these assumptions of ATIC's contribution to the prediction of job performance, we examine the question of whether ATIC predicts variance in job performance beyond the SI:

Research Question 1: Does interviewees' ATIC predict incremental variance in job performance above SI performance?

\section{Method}

Participants

Participants $(N=97,42$ males, 55 females, mean age $=29.48$ years with a SD of 4.75 ) were contacted with the help of the administrative departments of several universities and in collaboration with the career services of these universities. E-mails and advertisements were sent to current and prospective graduates who would soon be applying for jobs. Just over half of participants (55\%) already had a Master's degree or a comparable degree. Participants were allowed to participate if they were 
employed or very recently had been employed. Many participants held part-time jobs, which are very common where the study was conducted due to high living costs. The average work experience of participants was 2.77 years, and participants worked an average of $29.82 \mathrm{~h} /$ week. About $49 \%$ of participants worked in the research and education sector, $10 \%$ in the banking and insurance sector, $10 \%$ in the industrial sector, $9 \%$ in the service sector, $5 \%$ in the media and communication sector, $3 \%$ in health services, $2 \%$ in sales and distribution, and $1 \%$ in the public sector.

\section{Setting}

The present study relied on a research paradigm of a mock interview embedded in a selection training program for individuals who were about to apply for a new job. Similar approaches have been employed successfully in other studies (e.g., Barrick et al. 2010; Jansen et al. 2013; Van Iddekinge et al. 2005). Even though the mock interview was administered as part of a selection training program, participants perceived the setting as realistic, reported nervousness, and tried to perform at their best. In addition, participants had to pay a fee (approximately \$30) to cover expenses, which also helped to ensure that they took the study seriously. This setting enabled us to conduct the interviews under standardized yet ecologically valid applicant conditions. Moreover, because all participants were employed, we were able to collect job performance data from their supervisors that served as criteria.

\section{Procedure}

In the beginning of the selection training, participants were told to imagine that they were applying for a job as a management trainee, and a job advertisement was handed to them. This job was chosen because it represented an attractive and plausible position for candidates within diverse areas of study. Consistent with past research (e.g., Jansen et al. 2013; Klehe et al. 2008; Van Iddekinge et al. 2005), participants were informed that they would receive extensive feedback about their interview performance and that the top scoring participant on each day would win approximately $\$ 80$.

After the SI, participants were asked to fill in the ATIC measure. Participants were informed that this measure was not part of the simulated selection process and would be used for research purposes only. Around the time of the selection simulation, participants' supervisors were sent a link to an online questionnaire in which they were asked to assess participants' job performance. Supervisors were informed that their evaluations were confidential (i.e., that these ratings would not be given to their subordinates) and would be used for research purposes only. Interviewers had no access to participants' job performance ratings, and supervisors were not informed about participants' performance ratings in the SI.

\section{Interviewers}

Interviewers were students in a social and industrial/organizational psychology Master's program who volunteered as part of a research internship. All interviewers took part in a 5-h frame-of-reference training session (FOR, Melchers et al. 2011; Roch et al. 2012; Woehr and Huffcutt 1994) before the selection training. During the training, interviewers were introduced to the selection training, structured interview formats, the SI questions used in the study, and the interview scoring guide with its behavioral anchors. Afterward, interviewers practiced rating interview responses by watching example interviews and were provided with extensive feedback from the trainers (one author of this study and two continuously supervised industrial/ organizational Master students). Interviewers were not informed about the purpose of the study.

\section{Measures}

\section{$S I$}

The interview consisted of six situational questions with two questions for each of three targeted dimensions. According to O*NET, general management positions define leadership as a tendency to take charge and offer opinions and direction, persist in the face of obstacles and work activities that encompass Organizing Behaviors such as scheduling work and activities, coordinate the work and activities of others, and information ordering. Based upon the results from studying the requirements of management trainee positions, we thus chose the three interview dimensions of Assertiveness, Perseverance, and Organizing Behaviors. Furthermore, previous research had found support for the criterion-related validity of these interview dimensions in similar samples. For example, questions from the dimension Organizing Behaviors predicted job performance for a comparable sample in Jansen et al. (2013), Perseverance predicted job performance of college students in a study by Oswald et al. (2004). In addition, Assertiveness has been shown to be relevant to managerial performance (Borman and Brush 1993; Tett et al. 2000), has been used in previous interview studies (Klehe et al. 2008; Melchers et al. 2009), and can clearly be discriminated from the two other dimensions.

For the development of the interview, we contacted the authors of several previous studies and were allowed to adapt several of their interview questions (Jansen et al. 2013; Melchers et al. 2009; Peeters and Lievens 2006). 
After translating and adapting these questions to the management trainee position, three subject matter experts checked the suitability of the interview questions for assessing the targeted dimensions. These experts also checked whether the behavioral anchors fit to the question and covered the range of answers that were to be expected for the respective question. Examples for questions related to the different dimensions are shown in Appendix A.

All interviews were conducted by panels of two interviewers. For each question, both interviewers rated interviewees' answers on a five-point scale and we then averaged their ratings for each question. Behavioral anchors were provided for 1 =poor performance, $3=$ average performance, and $5=$ excellent performance. One interviewer read the questions and both interviewers independently rated the interviewee's response after each question. Interviewers were not allowed to probe. Across all interviews, the reliability of the average rating of the two interviewers across all questions was .82 (ICC 2; McGraw and Wong 1996), and the Pearson correlation between interviewers' ratings was $.70 .^{1}$

\section{$A T I C$}

We assessed ATIC following procedures used in previous studies (e.g., Jansen et al. 2011). Following the SI, participants completed a questionnaire in which each interview question was listed and space was provided underneath each question. Participants were instructed to write the dimension that they believed was assessed with each interview question, and to provide behavioral examples for this dimension (e.g., they wrote down Assertiveness as the targeted dimension and provided an example that someone would speak up for their rights as an employee). To ensure that participants understood this procedure, they received a neutral example on Creativity. They were able to write down as many dimensions and behavioral examples per interview question as they wished.

A pair of experienced raters (the first author of this study and a Master's student of social and industrial/organizational psychology) examined the assumptions and behavioral examples and rated the fit with the targeted dimensions on a scale from $0=$ no fit, $1=$ limited fit, $2=$ moderate fit to $3=$ fits completely. Raters discussed disagreements exceeding one-point, which was observed in $2.97 \%$ of cases. The interrater reliability of the averaged ATIC ratings from the two raters (ICC 2) was .95 before the discussion of their ratings and .97 after the discussion. The Pearson correlation across all of these ATIC ratings by

\footnotetext{
$\overline{1}$ As pointed out by a reviewer, these values might overestimate interrater reliability because interviewers in panel interviews observe the same random response errors (see Huffcutt et al. 2013).
}

the two raters was .90 before the discussion and .94 after the discussion of the ratings. The overall ATIC score was calculated based on the average score of the two raters across the six questions after the discussion of their ratings.

Job Performance We measured in-role performance using five items from Williams and Anderson (1991) in their German translation from Staufenbiel and Hartz (2000), and five items on task-based performance from Bott et al. (2003) in their German translation from Jansen et al. (2013). All items (see Appendix B) were rated on a seven-point scale ranging from $1=$ not at all to $7=$ absolutely. Due to the fact that the two sets of items were highly correlated $(r=.85)$, we computed a composite score across all items. Coefficient alpha of the combined scale was .94 .

Other Measures After the SI, participants completed a questionnaire concerning the authenticity of the interview situation on a scale from $1=$ I fully agree to $4=I$ fully disagree. The items were "Did you perceive the interview to be realistic?", "Did you feel like an applicant?", and "Did you behave as if being in a real interview?" At the end of the selection training, participants completed a questionnaire on socio-demographic variables.

\section{Results}

\section{Preliminary Analyses}

Results from the post-interview questionnaire showed that interviewees generally reported that they acted as if they were participating in a real selection interview $(M=3.40$, $\mathrm{SD}=.64$, on a scale from $1=I$ fully disagree to $4=I$ fully agree). Interviewees' overall SI performance correlated with supervisory ratings of their job performance, $r=.24, p<.05$ (Table 1). When one uses the mean interview interrater reliability estimate of .61 from Huffcutt et al. (2013) and the average job performance single-rater reliability of .52 from Rothstein (1990) to correct this correlation (which takes the correlation to a construct level), the correlation rose to .43 . When correcting for unreliability in the criterion only, the corrected correlation was .33. Thus, in line with previous meta-analytic evidence on SIs (e.g., Huffcutt et al. 2004), the present SI predicted job performance as rated by supervisors.

\section{Main Results}

Hypothesis 1 predicted that interviewees' ATIC scores would relate positively to performance in the SI. Table 1 shows support for this: Interviewees' ATIC scores 
Table 1 Descriptive statistics and intercorrelations of study variables
$N=97$

$* * p<.01 ; * p<.05{ }^{\dagger}$

$p<.10$ (two-tailed)

\begin{tabular}{|c|c|c|c|c|c|c|c|c|c|c|}
\hline & $M$ & SD & 1 & 2 & 3 & 4 & 5 & 6 & 7 & 8 \\
\hline Job performance & 5.90 & 0.95 & & & & & & & & \\
\hline \multicolumn{11}{|l|}{ Ability to identify criteria } \\
\hline Overall ATIC score & 1.46 & 0.61 & $.29 * *$ & & & & & & & \\
\hline ATIC persistence & 1.21 & 0.89 & $.27 * *$ & $.72 * *$ & & & & & & \\
\hline ATIC Assertiveness & 1.91 & 0.90 & $.17^{\dagger}$ & $.66^{* *}$ & .17 & & & & & \\
\hline $\begin{array}{l}\text { ATIC Organizing } \\
\text { Behaviors }\end{array}$ & 1.26 & 0.83 & .15 & $.71 * *$ & $.33 * *$ & $.18^{\dagger}$ & & & & \\
\hline \multicolumn{11}{|c|}{ Situational interview performance } \\
\hline Overall performance & 3.89 & 0.44 & $.24 *$ & $.23 *$ & $.24 *$ & .06 & .16 & & & \\
\hline Persistence & 4.02 & 0.60 & $.32 * *$ & .09 & $.23^{*}$ & -.01 & -.03 & $.78 * *$ & & \\
\hline Assertiveness & 3.86 & 0.56 & .09 & .13 & .10 & .11 & .05 & $.59 * *$ & $.21 *$ & \\
\hline Organizing Behaviors & 3.80 & 0.68 & .11 & $.25^{*}$ & $.19^{\dagger}$ & .04 & $.30 * *$ & $.78 * *$ & $.47 * *$ & .13 \\
\hline
\end{tabular}

large descriptively, we further tested the differences of the relation of SI and job performance before and after controlling for ATIC. Specifically, we followed suggestions by MacKinnon et al. (2002) and used Freedman and Schatzkin's test (Freedman and Schatzkin 1992). According to Monte Carlo simulations by MacKinnon et al. (2002), this is a powerful test that can be used to evaluate whether a regression coefficient significantly decreases once another variable is controlled in the regression analysis (which is comparable to the comparison between a zero-order correlation and the partial correlation described above). Thus, in the present situation, the Freedman-Schatzkin test evaluated the difference between the regression coefficient of the SI as a predictor of job performance and the regression coefficient of the SI when predicting job performance in a model that controls for the impact of ATIC on job performance. The Freedman-Schatzkin test achieves this by calculating the ratio of the difference between the unstandardized regression coefficients and a standard error based upon the variance and covariance of the adjusted and unadjusted regression coefficients (MacKinnon et al. 2002).

In line with the results from the correlation approach, the SI no longer predicted job performance when ATIC was controlled, $b=.42$, ns, even though it was a significant predictor without ATIC, $b=.53, p<.05$. The results from the corresponding $t$ test confirmed that the difference was significant, $t(95)=2.38, p<.05$. Hence, this provides further support for Hypothesis 3 .

Finally, Research Question 1 addressed whether ATIC would explain incremental variance in job performance beyond the SI. This research question was assessed with a hierarchical regression analysis (see Table 2). SI performance scores were entered in the first step and interviewees' ATIC scores in the second step. Results showed that ATIC explained incremental variance beyond the SI, $\Delta R^{2}=.05, p<.05$. 
Table 2 Hierarchical regression analyses predicting job performance from situational interview performance and the ability to identify criteria

\begin{tabular}{lllll}
\hline & Variable & $\beta$ & $R^{2}$ & $\Delta R^{2}$ \\
\hline Step 1 & SI performance & $.25^{*}$ & $.06^{*}$ & \\
Step 2 & SI performance & $.19^{\dagger}$ & $.11^{*}$ & $.05^{*}$ \\
& ATIC & $.23^{*}$ & & \\
& & & &
\end{tabular}

$N=97$, ATIC ability to identify criteria, SI situational interview

$* p<.05 ;{ }^{\dagger} p<.10$

\section{Discussion}

In the current study, we tested a conceptual explanation for why SIs predict job performance that is based upon interviewees' ability to discern evaluation criteria of the SI. By doing so, this study mirrors a recent focus on the interviewee in structured interview research (Huffcutt et al. 2011; Melchers et al. in press) and highlights the importance of considering interviewees' knowledge, skills, and abilities (such as ATIC) for detecting the mechanisms underlying criterion-related validity. Results from this study lend support for this explanation that focuses on interviewees' ATIC: SI performance correlated with interviewees' ATIC scores (Hypothesis 1), and interviewees' ATIC scores predicted supervisor-rated job performance (Hypothesis 2). In addition, we found that the relationship between SI performance and job performance became nonsignificant when controlling for ATIC (Hypothesis 3). Taken together, these findings support the relevance of ATIC as an additional explanation of the relationship between SI and job performance.

A major contribution of this study is that it helped to continue opening the "black box" of why SIs predict performance. At the same time, it illustrated what insights can be gained from research that aims at understanding interviewee performance. Results from this study underpin that interviewees that can decipher what the interview measures (i.e., ATIC) achieve better ratings in the interview, and above that, that ATIC is also relevant for performing well on the job. Thereby, the current study also provides empirical support for the fruitfulness of research that centers on interviewee performance and conceptualizes interviews as an interaction (Dipboye et al. 2012; Huffcutt et al. 2011; Levashina et al. 2013; Melchers et al. in press). As such, this study adds to recent research on how candidates make a good impression in interviews, hence to research on candidates' self-presentation in interviews (see Barrick et al. 2009, for an overview) or on interviewer's first impressions (Barrick et al. 2010, 2012).

A further contribution of this study is that it supports the idea that interviewees' ability to read situational demands in an interview is a job-relevant ability (Kleinmann et al.
2011). Although previous research suggested that ATIC can influence interview performance ratings, it was unclear whether identifying demands in the interview is good or bad for the criterion-related validity of interviews. The present results are consistent with previous findings in the AC domain (Jansen et al. 2013) in showing that candidates' ability to identify situational demands in selection procedures helps explains why the procedures predict job performance.

In light of results from this study, several recommendations can be made for selection practice. The first concerns the degree to which interviewees receive information about the targeted dimensions (i.e., evaluation criteria) before the interview (Klehe et al. 2008). The present results suggest, that when interview dimensions are made transparent to the interviewee, this should reduce the extent to which interviewees' ATIC is reflected in interview performance scores and might therefore also reduce criterionrelated validity. As a consequence, it follows that organizations should refrain from making interview dimensions transparent to interviewees.

A second recommendation relates to the relation of ATIC and job performance. Specifically, we found that ATIC was a better predictor of job performance $(r=.29)$ than was the SI itself $(r=.24)$. This finding parallels evidence from the study by Jansen et al. (2013) in which ATIC scores from an AC were a somewhat better predictor of job performance than was the AC. From an applied perspective, selecting candidates based on their ATIC scores may be possible and a promising approach.

Concerning future research, the evidence for the job relevance of ATIC implies that it is also relevant to conduct research on ATIC in actual work settings. In particular, we need to dig deeper into the mechanisms through which ATIC relates to job performance. One explanation from ATIC research is that employees scoring high on ATIC may show more evaluation-relevant behaviors that are reflected in enhanced job performance (e.g., Jansen et al. 2013). A complementary explanation for the positive relationship between ATIC and job performance could also be drawn from goal-setting theory (Locke and Latham 1990). A basic assumption in goal-setting theory is that the more specific a goal is, the higher is task performance, and meta-analytic research has clearly supported this relationship (Mento et al. 1987; Tubbs 1986). Linking both conceptual approaches to the job performance context, ATIC on the job may enable employees to identify job performance criteria. Accordingly, these insights might enable them to specify their goals from performing as well as possible to performing well with regard to specific criteria. Future studies might attempt to test this or other possible mechanisms that might explain why ATIC influences job performance. 
Although we found that ATIC contributes to the SI's prediction of job performance, we do not assume that this explanation is exclusive. Other contributing factors need to be tested in the future as the black box of why SIs predict job performance is not yet fully cracked open. For example, future research might consider a recent theoretical model on interviewee performance that focuses on interviewee and interviewer behaviors and dispositions as well as situational characteristics of the interview (Huffcutt et al. 2011). This may provide more insights about what interviewees do in the interview and how this affects the prediction of job performance (Dipboye et al. 2012; Levashina et al. 2013; Melchers et al. in press).

Related to this future research avenue on complementary explanations, we recommend that interview research continues adopting the perspective of the interaction of person and situation, hence following interactionist approaches (Mischel and Shoda 1995; Tett and Burnett 2003). Research on ACs has already illustrated how interactionist theories can contribute to a better understanding of personnel selection issues (e.g., Haaland and Christiansen 2002; Lievens et al. 2006), and we feel that interview research might profit similarly. In fact, as suggested by Jansen et al. (2011, see also Kleinmann et al. 2011) research on ATIC can also be framed in the context of the interactionist cognitive-affective personality system (CAPS) theory (Mischel and Shoda 1995). This theory posits that behavior results from cognitive scripts are activated in a situation, and that different behaviors can be shown depending on the respective script, which reflects the individual's perception of the situation. Applying this approach to ATIC, ATIC relates to these interindividual differences of reading the situation that in turn influence interviewees' performance (see also Jansen et al. 2013; Kleinmann et al. 2011). Future studies might examine how situational characteristics such as the degree of structure or rapport building moderate the relation of ATIC and interview performance. This may allow for improving interviews by optimizing situational characteristics such that they facilitate the expression of interviewees' job-relevant knowledge, skills, and abilities (such as ATIC) that influence interview performance and explain variance in job performance.

Finally, very little is known about factors that may influence whether someone is good or poor at identifying situational demands. Up to know, the limited available research has shown that ATIC is related to cognitive ability and social skills (Griffin 2014; Jansen et al. 2013; Kleinmann et al. 2011). Future studies could explore other factors, such as self-presentation (see Griffin 2014 as first study on nonverbal self-presentation and ATIC). Furthermore, we need to dig deeper into whether ATIC is a relatively stable individual difference or whether it may change as a consequence of experience in selection contexts or on the job as a result from feedback from others or training. Addressing these issues is also of practical relevance, because if trainable, ATIC may increase chances to get a job.

\section{Limitations}

Some limitations should be considered with regard to this study. One limitation is that participants were not interviewing for a real job. However, the post-interview questionnaire suggested that participants approached the interview as they would for a real job opportunity. Furthermore, the interview was related to supervisors' ratings of job performance, and the magnitude of the relationship was in line with meta-analytical findings on the criterionrelated validity of SIs (e.g., Huffcutt and Arthur 1994).

Second, as most interviewees were employed part-time, the results concerning the criterion-related validity of the interview dimensions might be relatively conservative. For example, our results indicated that Perseverance was the best predictor of job performance as compared to Assertiveness and Organizing Behaviors. However, as suggested by a reviewer, this might be due to the part-time nature of the jobs for which assertive behaviors or reorganization approaches may not be as important. As such, it is possible that the criterion-related validity and ATIC's capability to explain it may be stronger in full-time jobs.

\section{Conclusion}

In sum, the present study contributes to understanding the mechanisms by which the SI predicts job performance and highlights the insights that can be gained from research that focuses on factors contributing to interviewees' performance and job performance. The results support the idea that interviewees' ATIC measured in the SI predicts job performance, and that ATIC also helps explain the criterion-related validity of the SI. We look forward to future research on the nomological network of ATIC, interviewee-related factors, and research that takes an interactionist perspective on interviews to extend our understanding of the criterion-related validity of employment interviews and other selection procedures.

Acknowledgments The study reported in this paper was supported by a grant from the Swiss National Science Foundation (Grant 100014-124449). We thank Anne Jansen for her advice on the data collection. 


\section{Appendix A}

Situational Interview Instruction

In the following, we will interview you with 6 questions that relate to situations on your future job. Your task is to other work colleagues. You've invested a lot of time in generating and elaborating on the ideas. One colleague immediately questions the potential execution of the project and starts having private conversations. Please describe briefly how you would behave in this situation.

Performance assessment: Assertiveness

:

$\begin{array}{ll}\square & \square \\ 1 & 2\end{array}$

$\begin{array}{ll}\square & \square \\ 4 & 5\end{array}$

put yourself in different situations that an employee might experience in his or her on a work day and to tell the interviewers, how you would behave in the respective situation. Please listen attentively to each interview question and afterward take your time to answer each question. I will read out the questions and write down your answers. Do you have any questions before we start?

Sample Situational Interview Question for each dimension:

\section{Perseverance}

Imagine you're finding the first months at your new job very difficult. The tasks you're assigned are very demanding and you think your boss isn't entirely satisfied with your work. Please describe briefly how you would behave in this situation.

Performance assessment: Perseverance

Anchors:

5. Firmly asks the colleague to refrain from his or her conversations, addresses skeptical arguments and continues with the presentation.

3. Bides his or her time, tries to ignore the conversations and asks the colleague to stop after quite some time using a moderate tone or gives him or her disapproving looks.

1. Ignores the conversations or gives in and breaks off the presentation.

\section{Organizing Behaviors}

Please imagine the following situation. You return to your workplace after your holidays. You discover a stack of unopened letters on your desk and there are over 100

:

$\begin{array}{ll}\square & \square \\ 1 & 2\end{array}$

$\begin{array}{ll}\square & \square \\ 4 & 5\end{array}$

(:) 5
Anchors:

5. Speaks/interacts with his or her superiors and colleagues. Inquires about initiatives for further training, asks for tips on completing tasks efficiently. Is determined to improve himself/herself and to catch up in terms of performance. unread emails in your email inbox. There are already some meetings with clients planned for today. These meetings will take about an hour each. Furthermore, your boss wants to speak to you urgently about an issue. He has sent you details about it via email. Please describe briefly how you would behave in this situation.

Performance assessment: Organizing Behaviors

\section{(8)}

$\begin{array}{ll}\square & \square \\ 1 & 2\end{array}$

3. Works hard, tries to do his or her best and tries not to worry.

1. Is content with mediocre performance.

\section{Assertiveness}

Please imagine the following situation. You are presenting your newest idea for a project to your boss and
Anchors:

5. Proceeds in a systematic and structured manner, e.g., reads the e-mail from the boss first and only skims the most important messages, arranges and prepares for the meeting with the boss; asks less busy colleagues to take over tasks, etc. 
3. Tries to deal with everything on the first day and works overtime, reads messages in the breaks between the meetings or accepts that he or she will be unprepared when he or she meets with the boss.

1. No systematic approach evident, e.g., reads through the entire inbox first, cancels client meetings.

\section{Appendix B}

\section{Job performance measure}

Job performance was rated on a seven-point scale ranging from $1=$ not at all to $7=$ absolutely with the following two measures: First, task-based job performance with the following items from Bott et al. (2003) in the German translation from Jansen et al. (2013):

- Demonstrates expertise in all job-related tasks.

- Fulfills all the requirements of the job.

- Could manage more responsibility than typically assigned.

- Is competent in all areas of the job, handles task with proficiency.

- Plans and organizes to achieve objectives of the job and meet deadlines.

Second, in-role behavior was measured with the following items from Williams and Anderson (1991) in the German translation from Staufenbiel and Hartz (2000):

- Adequately completes assigned duties.

- Fulfills responsibilities specified in job description.

- Performs tasks that are expected of him/her.

- Meets formal performance requirements of the job.

- Neglects aspects of the job he/she is obligated to perform.

\section{References}

Bangerter, A., Roulin, N., \& König, C. J. (2012). Personnel selection as a signaling game. Journal of Applied Psychology, 97, 719-738. doi:10.1037/a0026078

Barrick, M. R., Dustin, S., Giluk, T., Stewart, G., Shaffer, J., \& Swider, B. (2012). Candidate characteristics driving initial impressions during rapport building: Implications for employment interview validity. Journal of Occupational and Organizational Psychology, 85, 330-352. doi:10.1111/j.2044-8325. 2011.02036.x.

Barrick, M. R., Shaffer, J. A., \& DeGrassi, S. W. (2009). What you see may not be what you get: Relationships among selfpresentation tactics and ratings of interview and job performance. Journal of Applied Psychology, 94, 1394-1411. doi:10. 1037/a0016532.

Barrick, M. R., Swider, B. W., \& Stewart, G. L. (2010). Initial evaluations in the interview: Relationships with subsequent interviewer evaluations and employment offers. Journal of Applied Psychology, 95, 1163-1172. doi:10.1037/A0019918.

Berry, C. M., Sackett, P. R., \& Landers, R. N. (2007). Revisiting interview-cognitive ability relationships: Attending to specific range restriction mechanisms in meta-analysis. Personnel Psychology, 60, 837-874. doi:10.1111/j.1744-6570.2007.00093.x.

Borman, W. C., \& Brush, D. (1993). More progress toward a taxonomy of managerial performance requirements. Human Performance, 6, 1-21. doi:10.1207/s15327043hup0601_1.

Bott, J. P., Svyantek, D. J., Goodman, S. A., \& Bernal, D. S. (2003). Expanding the performance domain: Who says nice guys finish last? International Journal of Organizational Analysis, 11, 137-152. doi:10.1108/eb028967.

Campbell, D. T., \& Fiske, D. W. (1959). Convergent and discriminant validation by the multitrait-multimethod matrix. Psychological Bulletin, 56, 81-105. doi:10.1037/h0046016.

Campion, M. A., Palmer, D. K., \& Campion, J. E. (1997). A review of structure in the selection interview. Personnel Psychology, 50, 655-702. doi:10.1111/j.1744-6570.1997.tb00709.x.

Conway, J. M., \& Peneno, G. M. (1999). Comparing structured interview question types: Construct validity and applicant reactions. Journal of Business and Psychology, 13, 485-506. doi:10.1023/A:1022914803347.

Cortina, J. M., Goldstein, N. B., Payne, S. C., Davison, H. K., \& Gilliland, S. W. (2000). The incremental validity of interview scores over and above cognitive ability and conscientiousness scores. Personnel Psychology, 53, 325-351. doi:10.1111/j.17446570.2000.tb00204.x.

Dipboye, R. L., Macan, T. H., \& Shahani-Denning, C. (2012). The selection interview from the interviewer and applicant perspective: Can't have one without the other. In N. Schmitt (Ed.), The Oxford handbook of personnel assessment and selection (pp. 323-353). New York, NY: Oxford University Press.

Ferris, G. R., \& Judge, T. A. (1991). Personnel/human resources management: A political influence perspective. Journal of Management, 17, 447-488. doi:10.1177/014920639101700208.

Freedman, L. S., \& Schatzkin, A. (1992). Sample-size for studying intermediate end-points within intervention trials or observational studies. American Journal of Epidemiology, 136, $1148-1159$.

Griffin, B. (2014). The Ability to identify criteria: Its relationship with social understanding, preparation, and impression management in affecting predictor performance in a high-stakes selection context. Human Performance, 27, 147-164. doi:10.1080/ 08959285.2014.882927.

Haaland, S., \& Christiansen, N. D. (2002). Implications of trait activation theory for evaluating the construct validity of assessment center ratings. Personnel Psychology, 55, 137-163. doi:10.1111/j.1744-6570.2002.tb00106.x.

Harris, M. M. (1999). What is being measured? In R. H. Eder \& M. M. Harris (Eds.), The employment interview handbook (pp. 143-155). Thousand Oaks, CA: Sage.

Huffcutt, A. I. (2011). An empirical review of the employment interview construct literature. International Journal of Selection and Assessment, 19, 62-81. doi:10.1111/j.1468-2389.2010. 00535.x.

Huffcutt, A. I., \& Arthur, W. (1994). Hunter and Hunter (1984) revisited: Interview validity for entry-level jobs. Journal of Applied Psychology, 79, 184-190. doi:10.1037/0021-9010.79.2. 184.

Huffcutt, A. I., Conway, J. M., Roth, P. L., \& Stone, N. J. (2001a). Identification and meta-analytic assessment of psychological constructs measured in employment interviews. Journal of Applied Psychology, 86, 897-913. doi:10.1037/0021-9010.86.5. 897. 
Huffcutt, A. I., Culbertson, S. S., \& Weyhrauch, W. S. (2013). Employment interview reliability: New meta-analytic estimates by structure and format. International Journal of Selection and Assessment, 21, 264-276. doi:10.1111/ijsa.12036.

Huffcutt, A. I., Van Iddekinge, C. H., \& Roth, P. L. (2011). Understanding applicant behavior in employment interviews: A theoretical model of interviewee performance. Human Resource Management Review, 21, 353-367. doi:10.1016/j.hrmr.2011.05. 003.

Huffcutt, A. I., Weekley, J. A., Wiesner, W. H., Groot, T. G., \& Jones, C. (2001b). Comparison of situational and behavior description interview questions for higher-level positions. Personnel Psychology, 54, 619-644. doi:10.1111/j.1744-6570.2001.tb00225.x.

Jansen, A., Lievens, F., \& Kleinmann, M. (2011). Do individual differences in perceiving situational demands moderate the relationship between personality and assessment center dimension ratings? Human Performance, 24, 231-250. doi:10.1080/ 08959285.2011.580805.

Jansen, A., Melchers, K. G., Lievens, F., Kleinmann, M., Brändli, M., Fraefel, L., et al. (2013). Situation assessment as an ignored factor in the behavioral consistency paradigm underlying the validity of personnel selection procedures. Journal of Applied Psychology, 98, 326-341. doi:10.1037/a0031257.

Kepes, S., Banks, G. C., McDaniel, M., \& Whetzel, D. L. (2012). Publication bias in the organizational sciences. Organizational Research Methods, 15, 624-662. doi:10.1177/1094428112452760.

Klehe, U.-C., König, C. J., Richter, G. M., Kleinmann, M., \& Melchers, K. G. (2008). Transparency in structured interviews: Consequences for construct and criterion-related validity. Human Performance, 21, 107-137. doi:10.1080/08959280801917636.

Kleinmann, M. (1993). Are rating dimensions in assessment centers transparent for participants? Consequences for criterion and construct validity. Journal of Applied Psychology, 78, 988-993. doi:10.1037/0021-9010.78.6.988.

Kleinmann, M., Ingold, P. V., Lievens, F., Jansen, A., Melchers, K. G., \& König, C. J. (2011). A different look at why selection procedures work: The role of candidates' ability to identify criteria. Organizational Psychology Review, 1, 128-146. doi:10. $1177 / 2041386610387000$

König, C. J., Melchers, K. G., Kleinmann, M., Richter, G. M., \& Klehe, U.-C. (2007). Candidates' ability to identify criteria in nontransparent selection procedures: Evidence from an assessment center and a structured interview. International Journal of Selection and Assessment, 15, 283-292. doi:10.1111/j.14682389.2007.00388.x.

Latham, G. P., Saari, L. M., Pursell, E. D., \& Campion, M. A. (1980). The situational interview. Journal of Applied Psychology, 65, 422-427. doi:10.1037/0021-9010.65.4.422.

Latham, G. P., \& Sue-Chan, C. (1999). A meta-analysis of the situational interview: An enumerative review of reasons for its validity. Canadian Psychology, 40, 56-67. doi:10.1037/ h0086826.

Leary, M. R., \& Kowalski, R. M. (1990). Impression management: A literature review and two-component model. Psychological Bulletin, 107, 34-47. doi:10.1037/0033-2909.107.1.34.

Levashina, J., Hartwell, C. J., Morgeson, F. P., \& Campion, M. A. (2013). The structured employment interview: Narrative and quantitative review of research literature. Personnel Psychology, 67, 241-293. doi:10.1111/peps.12052.

Lievens, F., Chasteen, C. S., Day, E. A., \& Christiansen, N. D. (2006). Large-scale investigation of the role of trait activation theory for understanding assessment center convergent and discriminant validity. Journal of Applied Psychology, 91, 247-258. doi:10. 1037/0021-9010.91.2.247.

Locke, E. A., \& Latham, G. P. (1990). A theory of goal setting and task performance. Englewood Cliffs, NJ: Prentice-Hall.
Macan, T. (2009). The employment interview: A review of current studies and directions for future research. Human Resource Management Review, 19, 203-218. doi:10.1016/j.hrmr.2009.03.006.

MacKinnon, D. P., Lockwood, C. M., Hoffman, J. M., West, S. G., \& Sheets, V. (2002). A comparison of methods to test mediation and other intervening variable effects. Psychological Methods, 7, 83-104. doi:10.1037/1082-989X.7.1.83.

Maurer, S. D., Sue-Chan, C., \& Latham, G. (1999). The situational interview. In R. W. Eder \& M. M. Harris (Eds.), The employment interview handbook. Thousand Oaks: Sage.

McDaniel, M. A., Whetzel, A. M., Schmidt, F. L., \& Maurer, S. D. (1994). The validity of employment interviews: A comprehensive review and meta-analysis. Journal of Applied Psychology, 79, 599-616. doi:10.1037/0021-9010.79.4.599.

McGraw, K. O., \& Wong, S. P. (1996). Forming inferences about some intraclass correlation coefficients. Psychological Methods, 1, 30-46. doi:10.1037/1082-989X.1.1.30.

Melchers, K. G., Bosser, D., Hartstein, T., \& Kleinmann, M. (2012). Assessment of situational demands in a selection interview: Reflective style or sensitivity? International Journal of Selection and Assessment, 20, 475-485. doi:10.1111/Ijsa.12010.

Melchers, K. G., Ingold, P. V., Wilhelmy, A., \& Kleinmann, M. (in press). Beyond validity: Shedding light on the social situation in employment interviews. In I. Nikolaou \& J. K. Oostrom (Eds.), Employee Recruitment, Selection, and Assessment: Contemporary Issues for Theory and Practice. Hove: Psychology Press.

Melchers, K. G., Klehe, U.-C., Richter, G. M., Kleinmann, M., König, C. J., \& Lievens, F. (2009). "I know what you want to know": The impact of interviewees' ability to identify criteria on interview performance and construct-related validity. Human Performance, 22, 355-374. doi:10.1080/08959280903120295.

Melchers, K. G., Kleinmann, M., Richter, G. M., König, C. J., \& Klehe, U. C. (2004). Messen Einstellungsinterviews das, was sie messen sollen? Zur Bedeutung der Bewerberkognitionen über bewertetes Verhalten [Do selection interviews measure what they intend to measure? The impact of applicants' cognitions about evaluated behavior]. Zeitschrift für Personalpsychologie, 3, 159-169. doi:10.1026/1617-6391.3.4.159.

Melchers, K. G., Lienhardt, N., Von Aarburg, M., \& Kleinmann, M. (2011). Is more structure really better? A comparison of frameof-reference training and descriptively anchored rating scales to improve interviewers' rating quality. Personnel Psychology, 64, 53-87. doi:10.1111/j.1744-6570.2010.01202.x.

Mento, A. J., Steel, R. P., \& Karren, R. J. (1987). A meta-analytic study of the effects of goal-setting on task-performance: 1966-1984. Organizational Behavior and Human Decision Processes, 39, 52-83. doi:10.1016/0749-5978(87)90045-8.

Mischel, W., \& Shoda, Y. (1995). A cognitive-affective system theory of personality: Reconceptualizing situations, dispositions, dynamics, and invariance in personality structure. Psychological Review, 102, 246-268. doi:10.1037/0033-295X.102.2.246.

Motowidlo, S. J. (1999). Asking about past behavior versus hypothetical behavior. In R. H. Eder \& M. M. Harris (Eds.), The employment interview handbook (pp. 179-216). Thousand Oaks, CA: Sage.

Oswald, F. L., Schmitt, N., Kim, B. H., Ramsay, L. J., \& Gillespie, M. A. (2004). Developing a biodata measure and situational judgment inventory as predictors of college student performance. Journal of Applied Psychology, 89, 187-207. doi:10.1037/00219010.89.2.187.

Peeters, H., \& Lievens, F. (2006). Verbal and nonverbal impression management tactics in behavior description and situational interviews. International Journal of Selection and Assessment, 14, 206-222. doi:10.1111/j.1468-2389.2006.00348.x.

Roch, S. G., Woehr, D. J., Mishra, V., \& Kieszczynska, U. (2012). Rater training revisited: An updated meta-analytic review of 
frame-of-reference training. Journal of Occupational and Organizational Psychology, 85, 370-395. doi:10.1111/j.2044-8325. 2011.02045.x.

Roth, P. L., \& Huffcutt, A. I. (2013). A meta-analysis of interviews and cognitive ability: Back to the future? Journal of Personnel Psychology, 12, 157-169. doi:10.1027/1866-5888/a000091.

Roth, P. L., Van Iddekinge, C. H., Huffcutt, A. I., Eidson, C. E., \& Schmit, M. J. (2005). Personality saturation in structured interviews. International Journal of Selection and Assessment, 13, 261-273. doi:10.1111/j.1468-2389.2005.00323.x.

Rothstein, H. R. (1990). Interrater reliability of job performance ratings: Growth to asymptote level with increasing opportunity to observe. Journal of Applied Psychology, 75, 322-327. doi:10. 1037/0021-9010.75.3.322.

Salgado, J. F., \& Moscoso, S. (2002). Comprehensive meta-analysis of the construct validity of the employment interview. European Journal of Work and Organizational Psychology, 11, 299-324. doi:10.1080/13594320244000184.

Seibert, S. E., Crant, J. M., \& Kraimer, M. L. (1999). Proactive personality and career success. Journal of Applied Psychology, 84, 416-427. doi:10.1037//0021-9010.84.3.416.

Speer, A. B., Christiansen, N. D., König, C. J., Melchers, K. G., \& Kleinmann, M. (2014). Establishing the cross-situational convergence of the ability to identify criteria: Consistency and prediction across similar and dissimilar assessment center exercises. Human Performance, 27, 44-60. doi:10.1080/ 08959285.2013.854364.

Staufenbiel, T., \& Hartz, C. (2000). Organizational citizenship behavior: Entwicklung und erste Validierung eines Meßinstruments [Organizational citizenship behavior: Development and validation of a measurement instrument]. Diagnostica, 46, 73-83. doi:10.1026//0012-1924.46.2.73.

Taylor, P. J., \& Small, B. (2002). Asking applicants what they would do versus what they did do: A meta-analytic comparison of situational and past behaviour employment interview questions. Journal of Occupational and Organizational Psychology, 75, 277-294. doi:10.1348/096317902320369712.

Tett, R. P., \& Burnett, D. D. (2003). A personality trait-based interactionist model of job performance. Journal of Applied Psychology, 88(3), 500. doi:10.1037/0021-9010.88.3.500.

Tett, R. P., Guterman, H. A., Bleier, A., \& Murphy, P. J. (2000). Development and content validation of a "hyperdimensional" taxonomy of managerial competence. Human Performance, 13, 205-251. doi:10.1207/S15327043HUP1303_1.

Tubbs, M. E. (1986). Goal setting: A meta-analytic examination of the empirical evidence. Journal of Applied Psychology, 71, 474-483. doi:10.1037/0021-9010.71.3.474.

Van Iddekinge, C. H., Raymark, P. H., Eidson, C. E., \& Attenweiler, W. J. (2004). What do structured selection interviews really measure? The construct validity of behavior description interviews. Human Performance, 17, 71-93. doi:10.1207/ S15327043HUP1701_4.

Van Iddekinge, C. H., Raymark, P. H., \& Roth, P. L. (2005). Assessing personality with a structured employment interview: Construct-related validity and susceptibility to response inflation. Journal of Applied Psychology, 90, 536-552. doi:10.1037/ 0021-9010.90.3.536.

Williams, L. J., \& Anderson, S. E. (1991). Job satisfaction and organizational commitment as predictors of organizational citizenship and in-role behaviors. Journal of Management, 17, 601-617. doi:10.1177/014920639101700305.

Woehr, D. J., \& Huffcutt, A. I. (1994). Rater training for performance-appraisal: A quantitative review. Journal of Occupational and Organizational Psychology, 67, 189-205. doi:10. 1111/j.2044-8325.1994.tb00562.x. 